\title{
Aplicación normativa de la compraventa internacional de mercaderías
}

\author{
Eduardo Calderón Marenco² \\ Universidad Centroamericana, Nicaragua \\ eduardo.calderon.marenco@gmail.com
}

Fecha de recibido: mayo 2017 / Fecha de aprobación: junio 2017

Este artículo de investigación aborda cinco aspectos técnicos torales de la Compraventa Internacional de mercaderías, a partir del análisis crítico de la Convención de las Naciones Unidas de 1980, celebrada en Viena. Así, el estudio presenta una visión global y estructural de la Convención, resaltando aspectos de especial relevancia, tales como: su ámbito de aplicación; la formación del contrato; el incumplimiento contractual y sus efectos; destacando su influjo en el ordenamiento interno, pues no obstante la uniformidad e internacionalidad de su carácter, la Convención podría considerarse como derecho nacional. También se abordan los antecedentes e importancia jurídico económica, destacándose las aplicaciones alternativas de otros instrumentos dirigidos a regular este negocio jurídico, que también se entre laza con la Lex Mercatoria como referente, para la aplicación e interpretación de las normas internacionales y nacionales. Asimismo, se incluye un detallado estudio sobre la norma y autonomía conflictual en el contexto de la mencionada Convención, y los desarrollos que este principio fundamental del Derecho Internacional Privado ha tenido en la aplicación de la misma.

\section{Palabras Clave}

Compraventa Internacional / Convención / Autonomía Conflictual / Mercaderías / Derecho uniforme

\section{Abstract}

This research paper addresses five technical aspects of the International Sale of Goods from critical analysis of its regulatory framework, namely the United Nations Convention of 1980, held in Vienna. Thus, the study presents a global and structural vision of the Convention, highlighting issues of particular relevance, such as its scope; the formation of the contract; the obligations of the parties; the contractual breach and its effects; highlighting its influence in domestic law, as though not uniformity and internationality of character, the Convention could be considered as national law. Legal history and economic importance are also addressed, highlighting alternative use of other instruments to regulate this legal business, also between with the Lex Mercatoria as a reference to the application and interpretation of international and national standards. In addition, a detailed study of the standard and conflictual autonomy in the context of the said Convention, and the developments that this fundamental principle of private international law has had on the application thereof is included.

\section{Key Words}

International Sale / Convention / Autonomy conflictual / Goods / Uniform law

\footnotetext{
${ }^{2}$ Investigación realizada en el marco del Programa de Doctorado "Cuestiones actuales del Derecho" 2da edición de la Universidad Centroamericana, Nicaragua.
} 


\section{Tabla de contenido}

Introducción. I. Reseña Histórica de la regulación de la compraventa internacional de mercaderías. I.I. Aspectos generales. I.2. Ley uniforme sobre compraventa internacional, (LUCI), y Ley uniforme sobre formación del contrato de compraventa internacional, (LUFC). I.3. Convención de Viena de 1980 sobre Compraventa Internacional de Mercaderías. 2. Normativas internacionales aplicables a la compraventa internacional de mercaderías. 2. I. La Autonomía Conflictual en la Contratación Internacional. 2. I.I. Convenio de Roma 1980 y Reglamento Roma I. Ley aplicable a las obligaciones contractuales. 2.I.2. Convención Interamericana sobre derecho aplicable a las obligaciones contractuales. 2.I.3. Convención de Viena de 1980. Perspectivas de un Derecho Uniforme. 3. Aspectos generales de la Convención de Viena de 1980 sobre compraventa internacional de mercaderías. 3.I. Naturaleza Jurídica. 3.2. Estructura. 3.3. Ámbito de aplicación. 3.4. Carácter dispositivo. 3.5. Aplicación como Lex Mercatoria. 3.6. Usos y costumbres. 3.7. El contrato de compraventa internacional de mercaderías. 4. La Convención de Viena de 1980 y la aplicación de la norma conflictual. Resultados y aportes. Lista de referencias.

\section{Introducción}

La compraventa internacional de mercaderías se destaca, hoy en día, como el eje central de las transacciones comerciales que se llevan a cabo a nivel internacional. Cierto es que el contrato de compraventa constituye un tipo contractual típico en todos los ordenamientos jurídicos nacionales; empero, la realidad demuestra que las normas que estos ordenamientos aportan, para conducir el comportamiento de los sujetos intervinientes en dicho acto, no resultan adecuadas para regular las transacciones internacionales, tomando en consideración las peculiaridades que estas últimas presentan, ignoradas por las normativas estatales que únicamente responde a un contexto nacional.

En razón de esto, es necesario destacar la importancia del estudio pormenorizado de la evolución normativa de la compraventa internacional de mercaderías, en busca de un derecho uniforme que facilite ofrecer soluciones adecuadas, distintas de las tradicionales normas de conflicto estatales, con las que los Estados, de forma individual, han tratado de regular la problemática derivada de los contratos internacionales, $y$ entre éstos, de los contratos de compraventa internacional.

Tal situación ha generado una doble reacción: primero, por de los Estados, que, con especial intensidad en las últimas décadas, han combinado la elaboración de normas materiales específicas para el comercio internacional con la conclusión de convenios internacionales de derecho conflictual en ese ámbito; $y$, segundo, por parte del propio colectivo de sujetos dedicados al comercio, que, con el propósito de eludir las soluciones nacionales, someten sus contratos a los usos del comercio y a los principios generales de la contratación internacional. De esta suerte, es posible hablar en estos momentos de tres niveles de normatividad en la materia: internacional, estatal y profesional.

Las regulación de este negocio jurídico en el ámbito internacional vienen dada por diversos instrumentos, tanto de derecho duro como derecho suave, tal es el caso de Convención sobre la Prescripción en materia de la Compraventa Internacional de Mercaderías de la misma CNUDMI y su respectivo protocolo de enmienda de 1974 o bien la Convención de las Naciones Unidas sobre la Utilización de las Comunicaciones Electrónicas en los Contratos Internacionales del año 2005; sin embargo en el presente artículo se dará especial atención al reconocimiento que otorga la Convención de Viena de 1980, a la compraventa internacional de mercaderías, tomando en consideración el principio de libertad contractual y los límites que para la autonomía conflictual determina el derecho aplicable al contrato que ocupa este estudio, así 
como la exposición de ideas, argumentos y contra argumentos de autores que se han dado a la tarea de abordar en diversas ocasiones mediante sus obras científicas el tema en cuestión.

\section{Reseña Histórica de la regulación de la compraventa internacional de mercaderías}

\section{I.I. Aspectos generales}

Es necesario comenzar por escudriñar los principales aspectos evolutivos de la compraventa internacional de mercancías, entendiéndose ésta como una operación meramente mercantil, cuando constituye una actividad de intermediación en el cambio, en tanto el comprador compra para revender o el vendedor vende una cosa que a su vez ha comprado para revender, de modo que se distingue de la compraventa civil que es un acto de consumo, diverso de la mercantil que pertenece a la zona del cambio, de la circulación de la riqueza, en la que su comercialidad se determina por la intención del sujeto, que no es otra sino la del propósito de especular, de traficar (Castrillón y Luna, 2003, p.93).

Tanto el comercio como la humanidad han sufrido desde el principio de los tiempos el factor evolutivo, el cual ha caminado de la mano según las necesidades del hombre. El intercambio de bienes, fundamental actividad para la subsistencia del ser humano, posee diferentes rasgos que exteriorizan la mercantilidad de estos actos, razón por la que a lo largo de su evolución, y partiendo de la costumbre como fuente del derecho, los sujetos partes de estas transacción han visto la necesidad de la creación de normas que generen derechos y obligaciones. El Estado, a partir del siglo XVI, muestra interés en homologar las normas mercantiles para todos sus ciudadanos, de tal modo que a la vuelta del siglo XVIII, la codificación de este derecho dio énfasis a su autonomía en relación a la creación de leyes específicas aplicadas no solo a comerciantes, sino a actos de comercio (Orúe Cruz, 20l4).

El origen de la compraventa se encuentra en transacciones simples entre particulares. No obstante, en su evolución esta figura ha roto fronteras territoriales con la finalidad de satisfacer las necesidades del ser humano; en consecuencia, el derecho mercantil, para dar protección a esta figura jurídica, ha encontrado una mayor aplicación fuera de la actividad legislativa de los Estados. Es así que la fuente principal de la misma son los tratados internacionales, la costumbre mercantil, los usos contractuales, las reglas adoptadas por instituciones gremiales, leyes modelo sugeridas por entidades internacionales, etc. (Oviedo Albán, 2003).

El desconocimiento del marco legal de esta figura pueda plantear un problema tanto jurídico como social, en el que se ven inmersos los contratantes de menor y mayor envergadura, según el acto de comercio. Por tanto, se hace necesario hacer referencia a un marco histórico de la compraventa mercantil y a su evolución normativa hasta el día de hoy, lo que nos permitirá comprender la relevancia que ha adquirido con el pasar del tiempo. Para este efecto debemos indagar entre diversos autores que abordan esta temática, con el propósito inicial de esclarecer la aplicación normativa de esta figura jurídica.

La reglamentación de la compraventa internacional remonta sus orígenes a 1930, cuando el Instituto Internacional para la Unificación del Derecho Privado (UNIDROIT) - a través de la sociedad de naciones distribuyó a los gobiernos dos proyectos de ley uniforme sobre la compraventa internacional. Estos proyectos contenían las bases necesarias para llevar a cabo las operaciones entre partes, pero la labor fue interrumpida con la segunda guerra mundial. El trabajo, fue retomado por el gobierno holandés en 195I, quien organizó una conferencia y sometió a consulta uno de los proyecto. Paralelamente UNIDROIT creó otro proyecto de ley uniforme sobre la formación del contrato de venta internacional de objetos corporales (LUFC) destinado a acompañar el proyecto de ley uniforme sobre la venta internacional de objetos mobiliarios corporales (LUVI). La conferencia de La Haya de 1964 adoptó las dos convenciones (AndradeAbularach, 200I, p. 3). 
Tomando como punto de partida la creciente liberalización del comercio y el proceso de integración económica de ese entonces, y remarcando la actuación de UNIDROIT al presentar los dos proyecto que regularían la figura jurídica que hoy estudiamos, se estuvo en la necesidad de proponer el tema de la unificación del derecho sobre compraventa internacional, trabajo encomendado en el año de 1930 a un selecto grupo de juristas liderados por Ernst Rabel y compuesto por Henri Capitant, Cecil James Barrington Hurst, M.Fehr, H.C.Guteridge, J.Hamel y OestenUnden, juristas representativos de diferentes sistemas quienes realizaron el estudio y se encargaron de la preparación de anteproyectos sobre compraventa internacional (Oviedo Albán, 20I I).

El trabajo encomendado concluyó con éxito a lo que se denominó el proyecto de ley uniforme de 1934 , el que se presentó al Consejo Directivo del Instituto UNIDROIT y en 1935 se puso a disposición de los gobiernos (Oviedo Albán , 20I I, p.7). En 1937 se creó un comité para su revisión, y en 1939 se aprobó el proyecto de ley uniforme sobre compraventa internacional de bienes corporales muebles, por parte del Consejo Directivo del Instituto UNIDROIT.

Oviedo Albán (20II) narra claramente el momento preciso de la composición de dos cuerpos legales que tendrían un claro declive en el intento de unificar el derecho internacional:

El advenimiento de la Segunda Guerra Mundial produjo la interrupción de los trabajos que serían retomados en $195 \mathrm{I}$ con ocasión de la Conferencia de La Haya sobre Derecho Internacional Privado, donde a iniciativa del Instituto UNIDROIT se aceptó examinar el proyecto de ley uniforme sobre compraventa internacional de bienes muebles. En 1956 se trabajó en una comisión de juristas europeos en un nuevo anteproyecto que fue remitido a diversos países con el ánimo de obtener comentarios. En 1962 se reunió nuevamente la Comisión, ocasión en la cual se decidió trabajar sobre dos anteproyectos sobre la venta internacional de cosas muebles y sobre formación del contrato. Estos anteproyectos serían estudiados en la Conferencia de La Haya sobre Derecho Internacional Privado de 1964 (p.8).

En ese entonces (a.1964) se dieron a la tarea 28 países de estudiar los dos proyectos y como resultado fueron aprobadas la Ley uniforme sobre la formación de los contratos de venta internacional de objetos muebles corporales (LUVI) y la Ley uniforme sobre formación de contratos de venta internacional de objetos muebles corporales (LUFC). Con dos instrumentos en vigencia, la uniformidad perdió sentido en su mayor esplendor, sin embargo no tomó mucho tiempo en que se reformara, no obstante es necesario conocer lo acontecido con ambas normativas.

\section{I.2. Ley uniforme sobre compraventa internacional, (LUCI), y Ley uniforme sobre formación del contrato de compraventa internacional, (LUFC)}

En 195I, el Gobierno de los Países Bajos convocó una Conferencia Diplomática a la que acudieron 20 países que después de estudiar el proyecto, decidieron constituir una Comisión Especial para la elaboración de un texto final. La Comisión elaboró un primer borrador en 1956 con su respectivo informe que fue objeto de comentarios por parte de los Gobiernos y de la Cámara de Comercio Internacional que dio lugar, en 1962, a una nota de la Comisión en las que estudió dichas observaciones y recomendó correcciones en la redacción del Proyecto (Martínez Cañellas, 2004, p.73).

Ampliando un poco más lo establecido por Oviedo Albán, cabe destacar que en 1963 estas modificaciones fueron incorporadas al Proyecto de Ley Uniforme sobre la Venta Internacional de Objetos Muebles Corporales, enviándose al Gobierno holandés al mismo tiempo que la propuesta de reunir en el tiempo más breve posible una Conferencia Diplomática. 
Por otro lado, en 1958, una Comisión del UNIDROIT había elaborado un proyecto de ley uniforme sobre la Formación del Contrato de Compraventa Internacional de Objetos Muebles Corporales que junto con el informe explicativo fue remitido al Gobierno holandés, que a su vez los remitió a los gobiernos interesados y a la Cámara de Comercio Internacional, que formularon sus observaciones.

Con ambos proyectos en mano, el Gobierno holandés convocó una Conferencia Diplomática, entre los días 2 y 25 de abril de 1964. Sin embargo, no se esperaban los resultados que tuvieron al final de ella donde se involucraron 28 países, y fueron como observadores otros cuatro países y seis organizaciones internacionales (Martínez Cañellas, 2004). La Conferencia acabó con dos Convenciones: una referente a la Ley Uniforme sobre la Compraventa Internacional de Mercaderías, y otra relativa a la Ley Uniforme sobre la Formación del Contrato de Compraventa Internacional.

Uno de los aspectos más interesantes tiene que ver con la entrada en vigencia de ambas normas, lo cual sucedió en 1972, donde solamente fueron ratificadas por Israel, Gambia, Gran Bretaña, Italia, Holanda, Bélgica, Luxemburgo, República Federal Alemana y San Marino. Israel no hizo ninguna reserva. A como destaca Martínez Cañellas (2004): "Prácticamente toda la jurisprudencia que versa sobre estas leyes uniformes es alemana y, en menor medida, holandesa, belga, italiana y de Israel. Ello explica que la doctrina y jurisprudencia alemanas sean las más abundantes en los primeros momentos..." (p.76). Es por eso que $\mathrm{LUCl}$ y la LUFC son prácticamente inexistentes.

Aquí podemos determinar que a pesar de que existían ambos documentos, no cumplían con los objetivos para los que fueron creados, regular la compraventa de mercaderías en el ámbito internacional, de tal manera que pronto debía existir una solución. Aquí vale la pena destacar la posición de Oviedo Albán (20l I), la cual comparto, en el sentido de que de todos modos, y a pesar de su fracaso, ambos instrumentos deben de tenerse como antecedente directo de la Convención de Viena 1980, no solamente por la intención que estuvo detrás de ellas, sino en especial porque, una gran parte de sus disposiciones, son en esencia el fruto de una labor de depuración, perfección y pulido de la normativa contenida en las convenciones de La Haya de 1964.

\section{I.3. Convención de Viena de 1980 sobre Compraventa Internacional de Mercaderías}

Antes de hablar sobre la creación de esta nueva norma internacional habrá que explicar el desarrollo de su formación, el cual se produce un par de años después de las convenciones de La Haya, el 17 de diciembre de 1966; de tal suerte que la Asamblea General de las Naciones Unidas fundó la Comisión de las Naciones Unidas sobre el Derecho Mercantil internacional (CNUDMI), más conocida por sus siglas en inglés (UNCITRAL), la cual fue, y sigue siendo, el patrocinador mundial de la Convención (Galán Barrera, 2003, p. 78).

La función de la CNUDMI es promover la progresiva armonización y unificación de la ley del comercio internacional, coordinando el trabajo de las organizaciones activas en este campo y animando la cooperación entre ellas, así como promover una mayor participación en los Convenios internacionales existentes y una más amplia aceptación de los modelos existentes y de las leyes uniformes, sobre todo este último punto por el descontento que existía por parte de muchos gobiernos sobre la poca implementación de un derecho uniforme. La primera medida que adoptó fue la remisión de los textos de la LUCl y la LUFC a todos los países miembros de las Naciones Unidas para que se pronunciasen sobre si se iban a adherir a los mismos o no y las razones de su decisión.

Para este fin se creó un nuevo grupo de trabajo el 26 de marzo de 1969. Los miembros del mismo fueron elegidos igualmente entre países de sistemas legales, sociales y económicos diferentes. Las primeras siete sesiones se dedicaron a la revisión de LUCI. En 1976, en el séptimo período de sesiones, acabó la revisión 
de la LUCl con un nuevo Proyecto de Convención de Compraventa Internacional de Mercaderías, que junto con el comentario preparado por la Secretaría constituyó la base del Proyecto redactado y aprobado por la Comisión en 1977, además se realizó un texto en relación a la formación y validez de los contratos partiendo de LUFC y en un proyecto de UNIDROIT sobre unificación de ciertas normas relativas a la validez. Se transmitió después a la Asamblea General que, en la Resolución 33/93 de 16 de diciembre de 1978, decidió convocar una Asamblea plenipotenciaria para considerar el proyecto de Convención (Martínez Cañellas, 2004).

Antes de que se configurara el nuevo texto mediante la convención convocada, ya tenía críticas positivas sobre su elaboración e implementación, así lo expresa Medina de Lemus (1992):

En cuanto a la crítica que merece el proyecto de Convención, ya había obtenido una favorable acogida por parte de los países que participaron en la UNCITRAL. Se dijo que constituía un serio avance sobre los textos antecedentes por que había tenido en cuenta los principios de la mayoría de los sistemas jurídicos y por qué estaba redactado de forma flexible, con simplicidad y claridad, reflejando una transacción equilibrada y cuidadosamente formulada entre los intereses de las partes (p.33).

Este proyecto alcanzó esta crítica por el arduo trabajo que se impregnó en esta convención donde acudieron 62 Estados y 8 Organizaciones Internacionales. De vital importancia rescatar que el espíritu de consenso que se había desarrollado en CNUDMI se mantuvo hasta el final, trabajo que dio frutos.

Los textos auténticos están en idioma árabe, chino, español, francés, inglés y ruso. Conforme a lo establecido en su artículo 99, la Convención entró en Vigor el $1^{\circ}$ de enero de 1988. Se ha destacado que los grupos de trabajo realizaron su labor libres de influencias políticas, así como que los países industrializados evitaron actuar como grupo y tratando de encontrar las soluciones más objetivas posibles evitando perpetuar normas provenientes de algún país en particular (Oviedo Albán, 20I I, p. I0).

Alcover Garau citado por Medina de Lemus (1992) manifiesta acertadamente que el mejor resultado desde el punto de vista doctrinario ha sido recoger en un solo texto los temas relativos a la perfección del contrato y al contenido del mismo, y de esta forma se logran los mismos resultados de las leyes anteriores, pero sin los inconvenientes de repeticiones y contradicciones que acarrean la existencia de dos textos.

Además de lo anterior, también la creación de esta norma tuvo un importante aporte para la configuración de un nuevo derecho internacional en el plano mercantil. De esta manera Adame Goddard (1994) apunta a que si bien el objetivo era definir un régimen uniforme para los contratos de compraventa internacional y procurar su implementación en legislaciones nacionales sobre la materia, también constituye un paso decisivo en la construcción de lo que puede denominarse un derecho mercantil internacional, con el ánimo de que facilite los intercambios de bienes, capitales y servicios en un monto que tiende a la globalización económica (fenómeno que tiende de acuerdo al nivel de intercambio de bienes alrededor del mundo), denotando la creación de un derecho supra nacional.

Actualmente, sin lugar a dudas, uno de los textos más relevantes de las últimas décadas y ha sido suscrita por más de 70 Estados con sistemas sociales, jurídicos y políticos diferentes, Fernández Rozas, Arenas García, \& De Miguel Asensio (2013) concuerdan con lo planteado por Adame Goddard tomando en cuenta que la Convención es la manifestación más relevante del denominado derecho uniforme de los negocios internacionales con el ánimo de facilitar al operador la previsibilidad del derecho, pero además ellos van más allá de una simple uniformidad, criterio que comparto plenamente, debido a que este instrumento no solo alimenta la uniformidad en las relaciones comerciales internacionales, sino que también consiste en 
ofrecer una mayor certeza jurídica a las partes en la contratación, para lo cual las normas se traducen en una expresión de la realidad comercial en la actual etapa de las transacciones mercantiles internacionales.

\section{Normativas internacionales aplicables a la compraventa internacional de mercaderías}

Respecto a las transacciones internacionales en materia de compraventa internacional de mercaderías, el Derecho Internacional se observó como una barrera artificial a la conducta de los comerciantes, por lo que se buscaron soluciones a los problemas de una manera práctica: creando Convenios regionales o internacionales que contienen reglas uniformes aceptables para el mayor número de países, que es a lo que actualmente llamamos el nuevo derecho uniforme, por el cual también se creó lo que hoy conocemos como la Convención de Viena de 1980, de la cual ya hemos conocido su antecedentes. Sin embargo, no solo este instrumento ha procurado la unificación de normas que erradiquen los conflictos entre derecho interno sino que también en el ámbito regional europeo y latinoamericano se han creado normas que regulen y fortalezcan la actividad comercial y contractual en el ámbito internacional, no obstante cabe señalar que son de carácter general y no específico a como lo es la Convención.

A como bien menciona el jurista mexicano clásico Barrera Graf; quien de hecho fungió como Jefe del Grupo de Trabajo de UNCITRAL para la creación de esta convención; citado por Escamilla Jaime (20I3), esta tendencia moderna ha configurado lo que denomina Derecho mercantil internacional y ha resurgido como:

Consecuencia tanto del auge de las transacciones comerciales internacionales, terrestres (entre los países de Europa, fundamentalmente) marítima y aéreas (en todo el mundo), como por la introducción, el perfeccionamiento, la expansión y las facilidades de las comunicaciones instantáneas (radio, televisión y medios electrónicos) todos los países reciben pronta y eficazmente todas las mercaderías de los países más lejanos del orbe, esto se denomina como parte de la interacción moderna del comercio, y el Derecho no debe ser nunca ajeno a la regulación de los fenómenos que se manifiestan rápidamente en el contexto internacional. Las fuentes del Derecho mercantil internacional como rama del Derecho privado internacional, son muy amplias y diversas, pero resaltan por su importancia las que a continuación se determinan como son los tratados y convenciones internacionales, las leyes modelo, las compilaciones de usos y costumbres, las cláusulas legales y las guías legales (p. 40).

En esta nueva manera de legislar, además de los Estados, han participado los interesados, es decir, los comerciantes directamente o por medio de asociaciones o agencias internacionales con el ánimo de velar por los intereses de los consumidores, y que los ciudadanos no queden desprotegidos, ya que se amparan bajo normas de ámbito nacional y regional, donde sí están representados.

De acuerdo a lo planteado por Martínez Cañellas (2004), esta legislación internacional puede crearse de dos maneras: mediante Convenciones Internacionales o bien Leyes Modelos. Las Convenciones internacionales son respetuosas con la soberanía nacional de los Estados, ya que son éstos los que las aprueban y las hacen nacer del seno de la voluntad de ellos mismos y normalmente se realizan con trabajos preparatorios en donde igualmente se ven involucrados comisiones o agencias internacionales de carácter oficial; sin embargo presenta la problemática de ser o no ratificada por los Estados, que ha de entenderse la buena fe de los mismo al momento de participar en la creación, no obstante también pueden existir reservas que impidan la plena vigencia del documento e imposibilite la uniformidad de la norma. 
Por otro lado, nos encontramos con las leyes modelo que usualmente son elaboradas por las agencias internacionales u organismos que no necesariamente vinculan en su creación a los Estados, a diferencia de las Convenciones ofrecen una notable ventaja en la elaboración, pero deben ser después incorporadas al Derecho interno mediante Ley formal, o bien incluidas en los contratos como norma reguladora de los mismos en virtud de la autonomía de la voluntad de las partes (Martínez Cañellas, 2004). También considero debe tomarse en cuenta como fuente del derecho mercantil internacional, los usos y costumbres, que en muchas ocasiones en virtud de la autonomía de la voluntad han apartado la aplicación de instrumento jurídicos. Aún podemos analizar algunos textos que brindan un complemento a la regulación de la compraventa internacional de mercadería en el contexto europeo y latinoamericano, que permiten escoger la ley o el derecho aplicable a una contratación, que es lo que hoy en día se conoce como autonomía conflictual.

\section{I. La autonomía conflictual en la Contratación Internacional}

Para comprender este tópico traigo a colación el concepto brindado por Leible (20I I):

La autonomía conflictual es el equivalente a la autonomía privada en el ámbito del Derecho internacional privado. Por autonomía privada entendemos la libertad de las partes de configurar sus relaciones privadas libremente y bajo su responsabilidad. La manifestación más importante de la autonomía privada es la libertad contractual, que concede a las partes el derecho a decidir por sí mismas si debe concluirse un contrato y con quién debe concluirse (libertad de contratación), y que contenido debe presentar el contrato (libertad de configuración). A ello se le añade en tercer lugar la libertad de forma, es decir, la ausencia de la obligación de concluir un contrato en forma escrita o en otra forma (p. 215).

A esto el autor también agrega la necesidad de diferenciar la autonomía privada de la autonomía conflictual, que concede a las partes de un contrato la libertad de elección del derecho, por ende las partes pueden decidir por ellas mismas a que derecho se somete la relación jurídica existente entre ellas, en este caso el que se aplicaría a una compraventa internacional de mercaderías. Oviedo Albán (20I2) agrega que en el Derecho Internacional Privado moderno se admite como regla general para la determinación de la ley aplicable a los contratos internacionales a la autonomía de la voluntad, en un doble alcance: material y conflictual. Material, por que las partes pueden determinar el contenido del contrato, ante lo cual habrá que reconocer la naturaleza supletiva de las normas legales respectivas, salvo los límites impuestos por las leyes imperativas; conflictual debido a que las partes pueden escoger la ley o el derecho que regirá el contrato.

Esto genera una seguridad jurídica preventiva, evitando conflictos posteriores innecesarios entre las partes, así mismo brindando la ley aplicable al juez para obtener una actuación jurisdiccional más transparente y objetiva que lleve a la realización de los intereses materiales de las partes puesto que les permite escoger el derecho que resulte más adecuado. También supone ahorros en costos de transacción, de información y autoriza escoger una ley neutral de forma que ninguna imponga la suya a la otra. Por ello, es considerada una de las reglas básicas aceptadas por el Derecho Internacional Privado contemporáneo de contratos (Oviedo Albán, 2012). Se hará referencia a la forma como se encuentra reconocida en los instrumentos de Derecho Internacional Privado tanto en el plano europeo como latinoamericano, así como del Derecho Uniforme. 


\section{I.I. Convenio de Roma 1980 y Reglamento Roma I. Ley aplicable a las obligaciones contractuales}

El Convenio de Roma nace en el proceso de fortalecimiento de la Unión Europea con la finalidad de brindar certeza jurídica a las contrataciones dentro de la región es así que se firma el 19 de Junio de 1980 la Convención de Roma -instrumento que busca una solución para el ejercicio de los derechos civiles y mercantiles europeos en un solo cuerpo normativo, proporcionando la opción uniforme de las reglas contenidas en las leyes domésticas de cada uno de sus miembros- lo esencial de este instrumento fue: I. Especificar y reconocer el carácter de internacionalidad del contrato, con lo cual se da la opción de que el mismo pueda ser sujeto a diversas jurisdicciones europeas $\circ$ inclusive extranjeras. 2. Establecer reglas para evitar conflictos de leyes negativos a nivel comunitario (Europeo). 3. Establecer los lineamientos básicos sobre los cuales se regirá la autonomía de la voluntad de las partes para contratar y por encima de la atracción jurisdiccional o inclusive sentimientos nacionalistas de los gobiernos de los Estados miembro, es decir, determinar la ley que aplicará a la contratación sin determinar un negocio jurídico especifico (Álvarez Vázquez, Arias Segura, De Mauleon Medina, González Enríquez, \& Hernández Rivera, 2005).

Tuvo una excelente aceptación más aun cuando el punto clave de la arquitectura del Convenio de Roma de 19 junio 1980 fue el principio de los vínculos más estrechos. Este principio garantizaba la aplicación al contrato de la Ley del Estado con el que dicho contrato presentaba la más estrecha vinculación; sin embargo para que este principio fuese justo para las partes, se hacía necesaria la realización de un Balancing Test (Lorente Martínez, 20I5) lo que ocasionó posteriormente un desbalance en la aplicación del mismo. En base a esto se tuvo que modificar a Reglamento según resolución $N^{\circ}$ 593/2008 del Parlamento Europeo y del Consejo de 17 de junio de 2008, el cual se conoce como El Reglamento Roma I, que es el fruto, en efecto, de la transformación del Convenio de Roma de 19 junio 1980.

El Reglamento Roma I contiene "normas de conflicto uniformes", iguales para todos los Estados miembros de la Unión Europea en materia de contratos internacionales. De modo que la Ley que rige un contrato internacional es la misma con independencia del Estado miembro cuyos tribunales 0 autoridades conozcan del asunto o litigio. Ello proporciona estabilidad legal a los contratantes, por lo que favorece la contratación internacional.

La base jurídica del Reglamento Roma I se encuentra, como es ampliamente conocido, en el artículo $8 \mathrm{I}$ del Tratado de Funcionamiento de la Unión europea. $Y$ es otra de las ventajas que ofrece esta regulación: la unificación de las normas de conflicto favorece la libre circulación de resoluciones judiciales. En conclusión, se potencia el principio del reconocimiento mutuo de las relaciones judiciales y otras decisiones.

Es importante destacar este instrumento en materia de compraventa internacional, siendo que cuando no resulte aplicable la Convención de Viena de 1980, ya sea por voluntad de las partes o por no ser estado miembro de la misma, la regulación de estas operaciones corresponderá a su propio sistema de derecho internacional privado para determinar la normativa aplicable y derivar de ella el derecho o derechos que regirán la operación, esto a criterio de la autoridad. Desde la perspectiva europea será el Reglamento Roma I de 2008 en la mayoría de los supuestos (Fernández Rozas, Arenas García, \& De Miguel Asensio, 2013). La aplicación universal de esta normativa, favorecerá que en la mayoría de los casos sea el instrumento aplicable. 


\section{I.2. Convención Interamericana sobre derecho aplicable a las obligaciones contractuales}

La Convención Interamericana sobre Derecho aplicable a los contratos internacionales fue aprobada en Ciudad de México el 17 de marzo de 1994, con ocasión de la Quinta Conferencia Especializada Interamericana sobre DIPr, celebrada entre el I4 y el I8 de marzo de 1994 (en adelante, Convención de México) y a como indica su Preámbulo, el propósito de sus redactores fue continuar el desarrollo progresivo y la codificación del DIPr como norma unificadora de derecho en los Estados miembros de la Organización de Estados Americanos (OEA) además de proseguir la armonización de soluciones en el ámbito del comercio internacional, y estimular el proceso de integración regional y continental, facilitando la contratación internacional y removiendo las diferencias que presenta su marco jurídico (Navarro Pentón, 2009), a diferencia del Reglamento de Roma, la aplicación de este instrumento tiene como finalidad las transacciones de comercio lo cual procura una mayor especificación de la norma aplicable.

Específicamente la Convención de México reconoce especialmente que el contrato se rige por el derecho elegido por las partes (autonomía conflictual), por ende el acuerdo de las partes sobre esta elección debe ser expreso o, en caso de ausencia de acuerdo expreso, debe desprenderse en forma evidente de la conducta de las partes y de las cláusulas contractuales, consideradas en su conjunto. Dicha elección podrá referirse a la totalidad del contrato o a una parte del mismo, según Oviedo Albán (20I2) esto ha sido reconocida por la doctrina como una de las innovaciones más importantes hechas por la Convención de México al Derecho Internacional Privado latinoamericano, fundada en el interés de dotar a los particulares de seguridad jurídica en el comercio internacional, mismo fin que persigue el Reglamento de Roma I.

Debe destacarse que existe una importante diferencia entre la fórmula europea y la latinoamericana, especialmente en cuanto al significado que puede tener la "ley" y el "Derecho" a escoger, y en especial a la posibilidad o no que tienen los contratantes para pactar como aplicable al contrato un instrumento que no tenga el carácter de ley estatal. En el caso europeo se ha asumido que cuando las partes escogen una determinada ley como reguladora del contrato, se entiende que se refieren a las normas materiales vigentes en el respectivo Estado, con exclusión de las normas de conflicto. (Oviedo Albán, 2012, p. I26).

\section{I.3. Convención de Viena de 1980. Perspectivas de un Derecho Uniforme}

Leible (20II), se cuestiona ¿Solución a través de una unificación internacional del Derecho de los contratos?, apunto que la respuesta a esta pregunta se vincula al propósito de realizar la unificación de derechos que en reiteradas ocasiones genera una mayor certeza. Para diversos autores como Fernández Rozas, Arenas García, \& De Miguel Asensio (2013), se han superado en gran manera las complicaciones en el comercio internacional derivadas sobre todo de la pluralidad de legislaciones, a como hemos referido en otras ocasiones, se manifiestan en todos los sectores y contratos pero son especialmente importantes en la compraventa por ser este el acto esencial del comercio.

El resultado de estos esfuerzos han sido una serie de prácticas comerciales concretadas en contratos tipo y en cláusulas tipo elaboradas por las asociaciones profesionales de comerciantes y Estados involucrados en el proceso de codificador y unificador de este sector en el ámbito internacional. Si hoy contamos con un instrumento de base, la referida Convención de Viena de 1980, su existencia y 
generalizada aceptación reposa en que está construida a partir de un importante sustrato de usos y prácticas de carácter profesional.

Oviedo Albán (2003), desde esta perspectiva, expone la diferencia entre la convención y los tratados de derecho internacional privado, que persiguen la determinación de la normativa aplicable a los contratos, como es el caso específico del Convenio de Roma de 1980 sobre ley aplicable a las obligaciones contractuales. En su adecuación de la comunicación de la Comisión al Consejo y al Parlamento Europeo menciona tales diferencias y se indica que:

La primera consiste en la aplicación de normas internacionales uniformes de derecho privado para determinar cuál es la normativa que rige el contrato. (...) La segunda solución consiste en armonizar las normas de derecho material a nivel internacional. En este caso, la norma más importante es la Convención de las UN sobre los contratos de compraventa internacional de mercaderías (CISG) (...) (p. 108).

Con ella se persiguió la creación de un marco legal único para el derecho de la compraventa internacional en un solo texto. Existía la intención de que la vida comercial tuviera un desarrollo ordenado y seguro, lo que se favorecería con el conocimiento inmediato de la ley aplicable a la transacción, por lo que se ha superado la desconfianza generalizada de gran parte de los Estados en ceder su soberanía legislativa, seguramente porque fue fruto de un amplio consenso entre países de muy distintos ámbitos jurídicos.

\section{Aspectos generales de la Convención de Viena de 1980 sobre compraventa internacional de mercaderías}

En diversas ocasiones hemos hablado sobre la importancia que adquirió la elaboración de este texto jurídico; sin embargo a partir de su implementación en diversos países de distintos continentes y diferentes realidades económicas, ha adquirido una relevancia tanto jurídica como económica, en este último aspecto la importancia de la Convención se manifiesta precisamente en países marcadamente orientados al comercio exterior, que en las últimas dos décadas ha tenido un crecimiento notable involucrando a países de economía de menor escala. Empero, todos los negocios de exportación e importación se realizan en todo el globo, por ende la convención también se ha aplicado en relación a otros Estados que son también importantes socios comerciales, pero que no son partes de este instrumento, debido a que siempre puede existir una negociación con una contraparte que ni siquiera tenga su establecimiento situado en un Estado contratante de la Convención; sin embargo, el ánimo comercial de crecer ha dotado a esta de gran valor su creación e implementación (Piltz, 1998).

Por otro lado, la relevancia jurídica, de la cual hemos venido comentando, está dirigida a regular de manera uniforme la operación típica del tráfico de mercancías, y que entre lazada con la relevancia económica, procura se agilicen las transacciones comerciales y se superen los obstáculos impuestos por la diversidad de criterios de las legislaciones nacionales, permitiendo hablar un lenguaje común mejor adaptado a las necesidades del comercio internacional, que además brinda una seguridad jurídica que reclaman las transacciones y reducen costos. 


\section{I. Naturaleza Jurídica}

El Doctor Oviedo Albán (20II) expresa que la Convención sobre Compraventa es de aquellos tratados denominados por la doctrina como tratado ley o tratados normativos que tienen por objeto formular una regla del derecho que sea objetivamente válida, como así lo ha sido este instrumento, y se caracterizan porque la voluntad de todos los signatarios tienen idéntico contenido además de ser inmediatamente aplicables sin necesitar desarrollos en el Derecho interno. Desde esta perspectiva, se puede destacar la diferencia entre la Convención y los tratados de Derecho Internacional Privado que persiguen la determinación de la ley nacional aplicable a las relaciones jurídicas privadas con componentes extranjeros.

Remarcando otro aspecto, la Convención hace parte de los elementos de Derecho (Hard Law) en tanto se manifiesta como instrumento internacional aprobado y ratificado por los Estados, y es que el concepto de Derecho Duro en esencia se refiere a los tratados y reglas adoptadas por los Estados, una vez adoptados, estos vinculan ante la ley; sin embargo por otra parte, en ciertas ocasiones la Convención puede aplicarse como instrumento de derecho suave (Soft Law) el cual tiende a ser definido como un conjunto de mecanismos, tales como declaraciones, resoluciones y programas de acción, que demuestran conformidad ante las normas establecidas por el Derecho Internacional pero no son vinculantes ante la ley (Galiana Saura, 2016), y tal es el caso cuando se aplica este instrumento en la contratación internacional no siendo parte del derecho interno de los Estados, es entonces que mediante la autonomía conflictual su aplicación es dispositiva, en líneas posteriores ahondaremos sobre esta temática.

\subsection{Estructura}

La Convención consta de I0I artículos divididos en cuatro partes. La Parte I define el ámbito de aplicación y contiene algunas disposiciones generales entre las cuales se encuentran reglas de interpretación de la Convención (Art. I-13). La Parte II regula la formación del contrato (Art. I424). La Parte III está dedicada a la ejecución o cumplimiento del contrato, incorporando la mayor parte de disposiciones sustantivas referidas a los derechos y obligaciones de las partes del contrato de compraventa internacional. La Parte IV, titulada "Disposiciones Finales", explica cómo un Estado puede adherirse a la Convención y que tipo de reservas puede imponer a su aceptación.

\section{3. Ámbito de aplicación}

Primeramente, habrá que establecer que este instrumento guarda plenamente un carácter internacional, sin embargo debemos remitirnos a los artículos I al 6que procura reproducir parámetros uniformes para el contrato de compraventa internacional (Oviedo Albán, 2003). Entre dichos parámetros está el mencionado en el artículo I, según el cual: "La presente Convención se aplicará a los contratos de compraventa internacional de mercaderías entre partes que tengan sus establecimientos en estados diferentes: a) Cuando esos estados sean estados contratantes; $\circ$ b) Cuando las normas de derecho internacional privado prevean la aplicación de la ley de un Estado contratante", este último inciso se refiere a la permisibilidad que da un Estado en caso de no ser contratante de poder someterse a la ley del Estado que sí es contratante, esto se abordará con mayor detalle en el desarrollo de este apartado.

En este sentido expresa Castellanos Ruíz (20ll) que es necesario enfatizar en el carácter internacional de la misma, posición que comparto atendiendo su naturaleza jurídica, sin embargo no 
es el único elemento que debe tomarse en cuenta para su aplicación. El Carácter internacional es completamente independiente de la nacionalidad del comprador y del vendedor, así lo establece el Art. I.3. Con todo, el objetivo de esta norma de carácter internacional es proteger la buena fe y, en general, la seguridad del tráfico, evitando que se aplique la Convención de Viena y se sorprenda así a la parte que contrató con la creencia de que se trataba de un supuesto de puro tráfico interno. Por tanto, el análisis de cada caso siempre estará sometido a las circunstancias concretas en que se hayan desenvuelto las relaciones entre las partes y si éstas conocieron de la internacionalidad de la situación o si objetivamente debieron conocerla para ser sujetos de aplicación de la Convención.

Para acortar este análisis, nuevamente siempre un punto de partida para determinar la internacionalidad de la operación es la ubicación de los establecimientos de los contratantes en Estados diferentes -único elemento que internacionaliza un contrato de compraventa objeto de regulación por la Convención de Viena-, con independencia del lugar de conclusión del contrato, del lugar en que estén situadas las mercancías o del lugar al que deban ser transportadas para su entrega (Castellanos Ruíz, 20I I, p. 88).

Para entender mejor este supuesto podemos traer a colación el siguiente ejemplo, no se regulará, por la Convención de Viena una compraventa celebrada entre un comprador francés y un vendedor alemán cuyo lugar de entrega de las mercancías sea Portugal si los contratantes tienen ambos sus establecimientos en Francia; a pesar de que objetivamente sí sea una compraventa internacional, aquí podemos notar que ambas partes tienen establecimiento en un mismo país. Por el contrario, puede regirse por la Convención de Viena la compraventa concluida por el comprador y el vendedor en el mismo Estado en el que se encuentran situados los bienes y en el que deben ser entregados, si una de las partes tiene su establecimiento en el extranjero.

La autora Castellanos Ruíz (20II) en su obra, considera necesario definir el término de establecimiento que no se estipula en la Convención, en tal sentido expresa:

Hay que entender por establecimiento toda instalación de una cierta duración, estabilidad y con determinadas competencias para dedicarse a los negocios. No es necesario que goce de autonomía jurídica, como establecimiento principal, sino que puede ser una simple sucursal o una oficina, ni tampoco que esté sometido a una dirección empresarial (p.89)

Galán Barrera (2004) agrega a esto, que no debe considerarse como establecimiento la residencia temporal de un contratante durante el tiempo en el cual se verifique la negociación, además habrá que tomar en cuenta, que ante la presencia de establecimientos múltiples, la Convención establece que se tendrá por tal, el que guarde la relación más estrecha con el contrato y su cumplimiento, habida cuenta de las circunstancias conocidas o previstas por las partes en cualquier momento antes o en el momento de la celebración del contrato.

A esta primera premisa, para determinar la aplicación de la Convención, se le debe entender como directa, sin embargo también cabe la aplicación indirecta de la misma. Esto también es conocido por Galán Barrera (2004) como ámbito espacial de aplicación en donde determina que si uno de los Estados no es contratante o, incluso, ambos no son contratantes, pero en virtud de las normas de Derecho Internacional Privado que correspondan se remite a la ley de un Estado contratante se aplicará indirectamente la Convención y en lo que considero puede tomarse como fuente de derecho y parte de la Lex Mercatoria que analizaremos posteriormente. Sin embargo no toda 
transacción estará bajo la protección jurídica de la Convención, es así, que debe tenerse en cuenta las exclusiones del artículo 2.

\subsection{Carácter dispositivo}

La Convención tiene carácter dispositivo, o sea que ella puede dejar de aplicarse de manera total o parcial si las partes del respectivo contrato internacional así lo estipulan o si los usos que ellas empleen tienen un alcance normativo distinto de lo previsto en la propia Convención, fundamento que atienden al pleno reconocimiento de la autonomía de la voluntad y que en su artículo 6 establece: "Las partes podrán excluir la aplicación de la presente Convención o, sin perjuicio de lo dispuesto en el artículo 12, establecer excepciones a cualquiera de sus disposiciones o modificar sus efectos". Claramente la convención tiene como principio fundamental el respeto a la autonomía de las partes y reconoce también la libre aplicación de los usos mercantiles (art. 9) para modificar, restringir, ampliar o anular una determinada relación comercial, mismo que una vez adoptados deben tener carácter obligatorio.

\subsection{Aplicación como Lex Mercatoria}

Oviedo Albán (20II), plantea acertadamente esta nueva tendencia sobre la inclusión de la Convención como Lex Mercatoria, en tal sentido nos comparte:

La Convención es aplicable a las transacciones que caigan bajo los criterios de carácter geográfico (art. $\mathrm{I}^{\circ}$ ), material (arts. 2, 3, 30 y 53) y temporal (art. 99). No obstante lo anterior, un grupo de laudos arbitrales, han adoptado la teoría de la aplicabilidad de la Convención como lex mercatoria, independientemente de que se presenten o no los factores indicados, al entender que en la medida en que la Convención es el reflejo de las principales reglas del contrato de compraventa, comunes a varios sistemas jurídicos, o de la costumbre internacional, resulta aplicable a los contratos internacionales. En este sentido, se abre camino a un concepto real de lex mercatoria, la cual, independientemente de su origen, legislado o no, contiene una serie de preceptos reguladores de dichos contratos. Igualmente, significa un rompimiento de los esquemas clásicos del Derecho Internacional Privado pues a diferencia de éste, que pretende encontrar la ley nacional aplicable, regula directamente los contratos internacionales extrayendo las reglas aplicables de la propia práctica de los comerciantes, de fallos y laudos arbitrales y de instrumentos internacionales que recojan reglas de aceptación universal (p. I8).

Efectivamente lo expuesto por él, debe considerarse como la configuración de una costumbre que se ha traducido a un instrumento legal proveniente de órganos supranacionales que recogen y reconocen tanto autonomía de la voluntad como usos y costumbres practicados en la compraventa internacional de mercaderías que permitan tanto a jueces y árbitros la implementación de la misma indistintamente que no estén en países contratantes. López Guzmán, Sánchez Morgestein, \& Quiroga Alarcón, (2009) definen la Lex Mercatoria como:

El conjunto de costumbres surgidas durante el medioevo como reglas propias de los comerciantes, las cuales dieron origen al derecho mercantil, el cual se caracteriza en su momento por ser de carácter profesional o subjetivo, consuetudinario, profesional y por haber desarrollado su propio sistema judicial con los tribunales consulares de justicia (p.28). 
Como podemos observar este concepto se ha creado mediante la fuente de la costumbre a como también se ha recogido en la Convención, sin embargo la Lex Mercatoria también debe evolucionar conforme el paso del tiempo razón por la que debe encontrar fundamentos no solo en usos y costumbres sino en instrumentos como la Convención que tenga sus mismos fundamentos, para este fin Oviedo Albán (20II) expresa que esta teoría se basa en los postulados relacionados a la existencia de un nuevo legislador transnacional, conformado por la misma sociedad internacional de comerciantes, de igual forma postula que se trata de una Lex Mercatoria que goza de plenitud, en el sentido de no necesitar de los derechos estatales por ende está plenamente vinculada a la autonomía de la voluntad, pero además está compuesta por principios generales del derecho de los contratos internacionales, usos y prácticas uniformes derivados y observados en la práctica comercial.

En otro aspecto el autor reconoce las variables de la Lex Mercatoria como ley del contrato que gravitan en torno a que sea la autonomía de la voluntad la que la invoque y en cuyo caso los árbitros la reconozcan reflejada en la Convención sobre Compraventa Internacional, o en su defecto, cuando no habiendo dicho nada sobre la ley aplicable, los árbitros decidan aplicar la Lex Mercatoria como ley del contrato y encontrar que aquella se encuentra reflejada en la Convención de Viena (Oviedo Albán, 20II, p.19).

\subsection{Aplicación de usos y costumbres}

A este análisis se le debe sumar el reconocimiento que otorga la Convención a los usos y costumbres que las partes invoquen al momento de desplazar el texto legal de la convención, Forero Jiménez citado por López Guzmán, Sánchez Morgestein, \& Quiroga Alarcón (2009) considera que estos (usos y costumbres) son completamente identificables con el concepto de Lex Mercatoria y que de igual manera a los tribunales internacionales frente a casos en los que no se encuentra ley aplicable a los contratos se les otorga herramientas para dirimir un litigio. Además la aplicación de los usos y costumbres del comercio internacional son fuentes de derecho y prevalecen sobre la Convención (Fratalocchi, 1994).

Correctamente la Convención ha previsto no dejar por fuera este tema de gran relevancia. Para Medina de Lemus (1992) el espíritu de una convención que contiene derecho uniforme es el de traducir las prácticas efectivamente en el comercio internacional, como así lo realiza el instrumento analizado, pero como texto necesariamente general trata de materias muy diversas y recoge usos que han sido ampliamente observados en numerosos sectores de actividad y con referencia a ciertos lugares geográficos y como se podrá observar se han utilizado como fuente de derecho.

La Convención de Viena prevé no solo la aplicación de los usos efectivamente convenidos entre las partes sino también aquellos que se consideran objetivamente aplicables al contrato. A los primeros se refiere al artículo 9.I expresivo de que las partes quedan obligadas por cualquier uso en que hayan convenido y por cualquier práctica que hayan establecido entre ellas. Para ello basta mencionarlos expresamente, es el caso de la aplicación de Incoterms, o deducirlos implícitamente de su comportamiento, interpretando la voluntad según las reglas ya examinadas, función que le tocará al órgano jurisdiccional o arbitral (Medina de Lemus, 1992, p.53)

Por su parte el artículo 9.2 señala que salvo pacto en contrario, se considerará que las partes han hecho tácitamente aplicable al contrato o a su formación un uso del que tenían o debían haber tenido conocimiento y que, en el comercio internacional, sea ampliamente conocido y regularmente observado por las partes en contratos del mismo tipo en el tráfico mercantil de que se trate. 
Es necesario determinar las dos condiciones para su debida aplicación, primero, que el uso sea conocido por las dos partes, lo que excluye a muchos de ellos, propios de países occidentales ajenos a los de en vías de desarrollo y la segunda condición, es que sea observado regularmente en el tipo de actividad y en el tipo de contrato. No es necesario que el uso sea universal pero si bien deben aplicarse al comercio internacional y no solo a las transacciones internas, además deben ser probados, determinándose la carga de la prueba por la lex fori, si la determinación se hace al margen de un litigio, corresponderá a aquel que los invoca (Medina de Lemus, 1992).Además de abordar los aspectos generales o más relevantes de la convención habrá que analizar las formalidades que recoge en materia de elaboración o estructuración del contrato de compraventa, así como obligaciones y derechos de las partes los cuales se abordarán en el siguiente acápite.

\subsection{El contrato de compraventa Internacional de mercaderías}

La Convención de Viena de 1980 dentro de su cuerpo normativo establece los términos generales que debe contener un contrato celebrado entre sujetos de diferentes países. Para Ortega Giménez (2009): "mediante el contrato de compraventa internacional de mercaderías, uno de los contratantes - denominado vendedor - se obliga a entregar una cosa determinada, y el otro -denominado comprador - a pagar por ella un precio cierto en dinero o signo que lo represente" (p.I).

Por otro lado, la Convención no define el concepto de compraventa para efectos de la determinación de su campo de aplicación, aunque los artículos 30 y $53^{3}$, plasman que compraventa será aquel contrato en que una parte (vendedor) se compromete a transferir el dominio de una mercadería, entregarla materialmente, y entregar cualesquier documentos relacionados con ella en las condiciones establecidas en el contrato y en la Convención, a cambio de las obligaciones de la otra parte (comprador) consistentes en el pago del precio de las mismas y su recepción (Oviedo Albán, 2004).

En este mismo sentido, Oviedo Albán (2009) aclara que la forma de articular estas disposiciones, de conformidad con algunos autores, es la determinación de las obligaciones del comprador de transferir la propiedad de las mercaderías vendidas y entregarlas materialmente, pero no regula los efectos que sobre la propiedad de las mismas pueda producir el contrato. Por otro parte, si el vendedor no cumple con dichas obligaciones, el comprador tendrá todos los derechos y acciones contra el vendedor por incumplimiento del contrato, consagrados en los artículos 46 a 52, y 74 a 77.

\footnotetext{
${ }^{3}$ Artículo 30 El vendedor deberá entregar las mercaderías, transmitir su propiedad y entregar cualesquiera documentos relacionados con ellas en las condiciones establecidas en el contrato y en la presente Convención.

Artículo 35 inc. I) El vendedor deberá entregar mercaderías cuya cantidad, calidad y tipo correspondan a los estipulados en el contrato y que estén envasadas o embaladas en la forma fijada por el contrato. 2) Salvo que las partes hayan pactado otra cosa, las mercaderías no serán conformes al contrato a menos: que sean aptas para los usos a que ordinariamente se destinen mercaderías del mismo tipo; b) que sean aptas para cualquier uso especial que expresa o tácitamente se haya hecho saber al vendedor en el momento de la celebración del contrato, salvo que de las circunstancias resulte que el comprador no confió, o no era razonable que confiara, en la competencia y el juicio del vendedor; c) que posean las cualidades de la muestra o modelo que el vendedor haya presentado al comprador; d) que estén envasadas o embaladas en la forma habitual para tales mercaderías o, si no existe tal forma, de una forma adecuada para conservarlas y protegerlas. 3) El vendedor no será responsable, en virtud de los apartados a) a d) del párrafo precedente, de ninguna falta de conformidad de las mercaderías que el comprador conociera o no hubiera podido ignorar en el momento de la celebración del contrato.
} 
La formación del contrato según la Convención viene dada por tres elementos fundamentales, oferta, aceptación y perfeccionamiento; sobre la oferta Cárdenas Mejía (2003) manifiesta que la Convención distingue, en primer lugar, entre oferta y la propuesta, esta última es una manifestación de voluntad orientada a celebrar un contrato, pero la misma no siempre es una oferta. En efecto, dentro del género de propuesta debe distinguirse entre la oferta y la invitación a hacer ofertas, así lo establece la Convención en su artículo 14: "La propuesta de celebrar un contrato dirigida a una o varias personas determinadas constituirá oferta si es suficientemente precisa e indica la intención del oferente de quedar obligado en caso de aceptación”.

Efectivamente no toda propuesta es una oferta, para Jaramillo Vargas \& Martínez Granados (2003) la oferta no es una invitación a entrar en negociaciones, ni es un acercamiento previo entre personas con intereses económicos comunes; al contrario, es un acto de mayor envergadura donde se observa un proyecto acabado de contrato que surge como conclusión de un periodo de negociaciones entre candidatos a ser partes, como consecuencia de una invitación a ofrecer (licitaciones), o bien como manifestación clara y unilateral de una persona que, interesada en celebrar una determinado contrato en determinadas condiciones, exterioriza su voluntad y lo propone a otra.

Un segundo requisito de la oferta es la precisión, la cual debe contener la exigencia de indicar claramente las mercaderías y de señalar, expresa o tácitamente, la cantidad y el precio o de prever un medio para determinarlos. Las ofertas referidas a géneros indeterminados, cuyas características particulares no se conocen ni pueden conocerse (no se fijan criterios) o cuyas cantidades son inciertas por tanto no serán válidas, se consideran como elemento material y de gran vitalidad por ser parte del objeto de este tipo de negociaciones y transacciones universales, pero generan seguridad jurídica en este tipo de actos.

El tercer y último elemento que establece la Convención para tener como válida una oferta, es la intención del oferente de quedar obligado en caso de aceptación, es decir, que se someta a las obligaciones contraídas a partir de la respuesta afirmativa del destinatario para que este quede obligado. Habiendo expuesto estos tres elementos de validez de la oferta, también debemos dejar sentado que toda oferta se vuelve efectiva una vez que llega al destinatario. Empero, todavía podemos encontrarnos frente a dos variantes: retirada y revocación de la oferta. En este sentido el catedrático Díez Picazo (2010) nos ilustra la diferencia entre ambas figuras:

La retirada es una declaración del oferente que indica su voluntad de dejar sin efecto una anterior declaración de la oferta, cuando ésta todavía no ha alcanzado efectividad. Existe retirada en el período de tiempo o en la fase de formación que media entre emisión de la oferta y la recepción o llegada de la misma al destinatario. En cambio, revocación es la declaración de voluntad de cancelación de la oferta y de sus efectos, en el período que media entre la recepción de la oferta y la perfección del contrato. La consecuencia práctica más importante de la distinción es permitir la retirada de las ofertas cuando éstas sean irrevocables. La retirada de la oferta es, lógicamente, libre y está sometida únicamente al requisito de la tempestividad. Se refiere a una declaración que no ha alcanzado ninguna forma de efectividad. El destinatario de la retirada no puede alegar ningún justo motivo para impedir dicha retirada, puesto que ningún tipo de confianza, ni de interés atendible, podría haberse creado en él (p.38).

De igual manera podemos destacar supuestos en que la Convención establece que la oferta no puede revocarse. Así lo determina el artículo 16, en los casos que se indica un plazo fijo para la aceptación o bien si el destinatario podía razonablemente considerar que la oferta era irrevocable y ha actuado basándose en esa oferta. Una vez configurada la oferta esta puede tener dos panoramas 
por parte del destinatario: rechazo o aceptación, entiéndase este último término como la manifestación de voluntad que perfecciona el contrato. Exigiéndose los siguientes elementos de declaración o acto del destinatario y cumplimiento del plazo para manifestar la aceptación.

Es así que Góngora Guzmán \& Martínez Olivas (2014) consideran que la aceptación es una declaración de voluntad emitida hacia el oferente, en la que se expresa la plena conformidad con las estipulaciones de la propuesta, aceptando celebrar el contrato. Por su parte, la Convención considera aceptación a toda declaración u otro acto del destinatario que indique asentimiento a una oferta (Artículo 18. Inc. I). Ahora bien, lo que si hay que tener presente es que sin aceptación no hay contrato, puesto que este es el punto final de la manifestación del consentimiento, y por ende la perfección definitiva del contrato, mismo fin que persigue la Convención de Viena.

Al igual que la oferta, la aceptación puede ser retirada teniendo en cuenta que la aceptación se emite en ejercicio de la autonomía de la voluntad del destinatario y que solo surte efectos una vez llegue al oferente (Artículo 22), por ende el retirar su aceptación deberá realizarse antes de que esto ocurra. En caso que existiere aceptación, se considerará como respuesta afirmativa y conllevará la perfección el contrato, como último elemento de formación del mismo; sobre este tema no existe la clave, sino que es entender que el contrato se perfecciona cuando el oferente efectivamente recibe la aceptación de la oferta. Excepto si en virtud de los términos de la oferta o de las prácticas que las partes hayan establecido entre ellas, el destinatario de la oferta la ha aceptado al momento en que realiza actos ejecutorios del mismo.

\section{La Convención de Viena de 1980 y la aplicación de la norma conflictual}

El artículo I.I a) de la Convención materializa la aplicación de la norma de forma directa hacia los Estados partes. Sin embargo, su aplicación resulta ser más amplia, así lo manifiesta el artículo I.I b) ${ }^{4}$ y ha de entenderse que esta es de manera indirecta, lo que conlleva al análisis de las normas de conflicto que deberán de tomarse en cuenta, así como la autonomía conflictual en relación a la Lex Mercatoria. En este mismo sentido, debemos dejar primeramente claro el concepto doctrinal de norma de conflicto, que es ampliamente reconocido por el Derecho internacional privado: según González Martin \& Rodríguez Jiménez (2010) este tipo de normas: "determina que ordenamiento jurídico, que sistema jurídico, de los que se encuentran razonablemente vinculados con el supuesto de hecho dará respuesta al fondo de la cuestión planteada por las partes, a través de sus normas materiales o sustantivas" (p.138).De este concepto brindado podemos determinar que más que un tipo de normativa, estas (nomas de conflicto) son un mecanismo que determinará en el momento de un conflicto entre las partes el derecho que se aplicará por parte del tribunal competente para poder dirimirlo.

Para Savigny (quien postuló este nuevo concepto) dos elementos dentro de la relación, a saber, el fáctico y el jurídico, son de vital importancia; pues a determinados hechos de la vida de las personas cada legislador asocia determinadas reglas; de modo que los elementos fácticos de una relación jurídica pueden conectarla con más de un ordenamiento, y en relación al caso no importa cómo es la compraventa internacional de mercaderías. En este este sentido, ideó el paradigma científico que llamó: "norma de conflicto"; instrumento que permite articular mediante la "declaración de aplicabilidad" del Derecho con una relación (a través de la consecuencia jurídica de la norma de

\footnotetext{
${ }^{4}$ Artículo I. I) La presente Convención se aplicará a los contratos de compraventa de mercaderías entre partes que tengan sus establecimientos en Estados diferentes:..b) cuando las normas de derecho internacional privado prevean la aplicación de la ley de un Estado Contratante.
} 
conflicto); dando relevancia para ello a un elemento concreto de la misma (el "punto de conexión") que sirve para hallar la "sede" de ésta (derecho aplicable) (Michinel Álvarez, 20I2).

Habrá que destacar que la norma conflictual también recurrirá como primer aspecto para resolver lo controvertido de la legislación aplicable al problema como tal, la llamada autonomía conflictual término que abordamos con anterioridad- que opera en la mayoría de los contratos de carácter internacional, así nos lo manifiesta Dávalos Fernández (2003):

«La autonomía de la voluntad conflictual sólo opera, en puridad, respecto de contratos internacionales», ya que, de esta forma, el calificativo «conflictual» ciñe el tema de la autonomía de la voluntad como la facultad de las partes en el contrato para elegir el Derecho aplicable, separándolo de la autonomía de la voluntad en sentido amplio, que es consustancial al contrato, pues como bien señala el profesor de París, C. Larrroumet, este principio supone que los intercambios económicos se realizan por medio de concesiones recíprocas, que son el resultado de las voluntades de los contratantes. La voluntad es soberana para conducir a la celebración del contrato y para determinar sus efectos. De esta manera, desde el ángulo del Derecho internacional privado, es admitido que: «las partes pueden elegir la ley aplicable a un contrato internacional, no a un contrato interno (p.7).

De esta forma, la norma conflictual pudiera tener asidero al momento de la escogencia de una ley aplicable al instrumento, cuando así las partes determinan a la Convención como Ley aplicable de forma directa. Sin embargo, concatenado con lo establecido en la Convención, la norma conflictual en el derecho moderno no puede solo procurar la remisión de una legislación de un Estado sino que es admisible el reconocimiento, fruto de la autonomía de la voluntad, de la Lex Mercatoria o usos y costumbres que así dispongan las partes, cuando se procura suplir la ausencia de regulación legal adecuada para el negocio jurídico que se realiza o bien únicamente hacer vida de un uso que constantemente se repite entre ambas partes; colmar las lagunas que existan en el contenido de los contratos o, sencillamente, coadyuvar a resolver las dudas que surjan en la interpretación de éstos y prácticas comerciales internacionales (Dávalos Fernández, 2003).

La Convención reconoce plenamente la aplicación de usos y costumbres, que además pueden desplazar a este cuerpo normativo. Así mismo, la Convención puede ser utilizada como Lex Mercatoria en el caso que nos compete, cuando dos Estados no son partes -aplicación del artículo I.I b)-. Sin embargo, Juenger \& Sánchez Lorenzo (2000) plantean una posición diferente, en el sentido que la le Lex Mercatoria pretende regular las situaciones diversas de un negocio jurídico de forma directa, sin intervención de normas conflictuales, posición con la que no estoy de acuerdo, debido a que la norma conflictual tomada como un mecanismo para definir la aplicación de un ordenamiento, puede definir a la Convención como la norma a aplicarse por parte de los tribunales, cuando así lo permitan las normas de Derecho Internacional Privado en Estados que no son parte, y más aún cuando no se ha establecido desde la autonomía conflictual la determinación de un derecho que regirá el contrato, por ende debe tener una vinculación vigente entre ambos mecanismos y la Lex Mercatoria como derecho de la materia.

Continuando con este intercambio de ideas y análisis desde el punto de vista doctrinario, y en tal sentido podemos preguntarnos: ¿Qué utilidad tendrá la norma conflictual para la Convención de Viena de 1980? Para dar respuesta a esto debemos retomar la problemática que puede plantear el ámbito de aplicación de la Convención establecido en el artículo I.I b), y en tal sentido se es consciente de las limitaciones que posee y por ello va a conceder cierta relevancia a la norma de conflicto. En primer lugar para amplificar su repercusión y superar el marco restringido de aplicación 
que resulta de depender de un criterio de reciprocidad; $y$, en segundo término, se recurre a esta norma de conflicto con el ánimo de designar el derecho nacional que suplemente sus carencias (Campuzano Díaz, 2000, p. I54).

Para Santos Belandro (2006), las normas de conflicto también entran en juego cuando existen reservas por parte de los Estados en relación al artículo que establece que: "Todo Estado podrá declarar en el momento del depósito de su instrumento de ratificación, aceptación, aprobación o adhesión que no quedará obligado por el apartado b) del párrafo I del art. I de la presente Convención".

Es decir, que la aplicación de la convención para los Estados que realicen esta reserva será de manera directa únicamente, esto, a como bien lo recoge la doctrina, procura únicamente favorecer la aplicación del derecho interno dejando por fuera las normas de Derecho Internacional Privado del tribunal competente, en razón de señalar como aplicable la ley de un Estado contratante. Sin embargo, únicamente han formulado una reserva de este tenor Canadá respecto de la Columbia Británica, Checoslovaquia, en su momento (ahora Republica Checa), China, Estados Unidos de América y Singapur.

En estos casos también habrá que atenderse a la competencia que se le designe al tribunal, y en estos casos podemos mencionar diversos supuestos: en primer lugar, la Convención dispone que para regular el contrato se habrá de recurrir al ordenamiento nacional designado por las reglas de conflicto del tribunal competente, para determinar el derecho aplicable en el caso de que no existan reservas por ambos Estados contratantes en relación al artículo en discusión (Santos Belandro, 2006).

Indudablemente, acá la competencia legislativa que eventualmente se le otorgue a la Convención va a quedar subordinada a la respuesta que se dé al problema de la competencia judicial. No obstante, en este supuesto nuevamente cabe resaltar que el Estado no contratante, en sus normas de Derecho Internacional Privado, puede remitir a la Ley del Estado de la otra parte, quien si incorporó en su legislación la Convención como derecho, por tanto puede aplicarse al negocio jurídico o bien, insisto, como Lex Mercatoria en sentido material.

En un segundo supuesto, si el tribunal competente es el de un Estado que realizó la reserva del artículo I.I.b. se deberá aplicar indudablemente su derecho interno, ya sea uno específico para las relaciones internacionales o aquél ya dispuesto para regular las relaciones internas, y nuevamente vemos como se configura la norma de conflicto. Otro supuesto a traer a colación es cuando el tribunal competente es el de un Estado contratante que no realizó ninguna reserva, y sus normas de Derecho Internacional Privado indican la aplicación de la legislación de un Estado contratante que sí realizó la reserva del artículo l.I.b. Aquí nos preguntamos ¿Qué ha de suceder en este caso? El Estado que no realizó la reserva no tiene facultades para imponer al tribunal competente que aplique su legislación interna en lugar de la Convención de Viena, por cuanto la reserva solo vincula al Estado que la interpuso y no a los demás (Santos Belandro, 2006).

Para concluir con este apartado, conviene exponer lo expresado por Ferrari (2009):

...no resulta sorprendente que se haya afirmado que la Convención de Viena crea una distinción entre dos tipos de contratos de compraventa de mercaderías: los contratos a los que la Convención de Viena se aplica y a los contratos a los que no se les aplica y que, por tanto, se rigen por derecho interno aplicable (p.77). 
En definitiva, lo expuesto por este autor materializa la necesidad de recrear los supuestos en que la Convención de Viena y su aplicación, de conformidad al artículo I.I.b, debe recurrir a las normas de conflicto, así como a la autonomía conflictual en relación a la aplicación del derecho, cuando existen contratos que no serán regidos por este instrumento. Cuestión que no ha dejado por fuera la Convención y certeramente ha previsto la imposición de normas de derecho internacional privado cuando así lo delimiten los Estados.

\section{Resultados y aportes}

Los esfuerzos que en las últimas décadas se han desarrollado para conseguir la unificación del régimen jurídico aplicable a la compraventa internacional de mercaderías en Europa y Latinoamérica han sido verdaderamente importantes y de un avance significativo realizado a gran velocidad, tomando en consideración el auge del comercio y el abatimiento de fronteras con relación al intercambio de bienes y servicios. Estas circunstancias surgieron a raíz de la necesidad de crear normas y reglas de derecho uniforme que regularan este tipo de actos, sin embargo en el proceso, existieron diferencias marcadas que evitaron en cierto momento el objetivo perseguido, existiendo hasta dos normativas que regularan la misma materia generando conflictos de aplicación entre ellas; sin embargo se corrigió esta situación con la aprobación de la Convención de Viena de 1980 sobre compraventa internacional de mercaderías.

Además de esto se debe remarcar que el desconocimiento del marco legal de la compraventa internacional en un primer momento causó un problema tanto jurídico como social razón por la que el estudio de la evolución normativa hasta el día de hoy, permite comprender la relevancia que ha adquirido con el pasar del tiempo dando como resultado un derecho uniforme que si bien es cierto aun no acabado; no obstante con un mejor perfil para su implementación y desarrollo.

La Convención es de los textos más relevantes de las últimas décadas y ha sido suscrita por más de 70 Estados (no incluyendo a Nicaragua) y va más allá de una simple uniformidad de derecho, sino que también ofrece de manera certera seguridad jurídica a las partes en la contratación en las transacciones mercantiles internacionales. De igual forma esta debe considerarse como fuente del derecho que a su vez materializa los usos y costumbres, como norma supletoria, previendo su propia carencia de disposiciones normativas en ciertas circunstancias. Para este efecto la autonomía de la voluntad goza de pleno reconocimiento con el ánimo de superar las complicaciones en el comercio internacional derivadas sobre todo de la pluralidad de legislaciones.

La Convención es un instrumento idóneo mas no perfecto, no obstante su fin último es brindar un derecho aplicable al elemento internacional de la compraventa de mercaderías, es por esta razón que la misma define claramente cuando ha de entenderse el supuesto de internacionalidad, fuera de esto no será posible su aplicación; no obstante en el ámbito espacial podemos encontrar el supuesto en que si uno de los Estados no es contratante o, incluso, ambos no son contratantes, su invocación como derecho de un contrato estará sometida de manera indirecta a su uso como Lex Mercatoria, lo que ha significado un rompimiento de los esquemas clásicos del Derecho Internacional Privado. En este mismo sentido es necesario concluir que la Convención tiene carácter dispositivo, respetando la autonomía de las partes de tal manera que puede ser excluida o bien puede tomarse en cuenta la libre aplicación de los usos mercantiles para modificar, restringir, ampliar o anular una determinada relación comercial en relación a este instrumento.

La Convención a pesar de su afán de crear derecho uniforme establece cláusulas muy generales en la determinación de las obligaciones de las partes así como los mecanismos de oferta y aceptación, razón por lo que las partes atienden siempre a la autonomía de la voluntad, los usos y costumbres 
para pactar lo que la convención no regula. Los redactores de la misma al parecer estaban conscientes de esta deficiencia por lo que salvaron estas situaciones dejando establecido este principio; sin embargo aún existen problemas que el derecho uniforme no resuelve, he aquí la invocación de la norma de conflicto y su relación con la Convención.

La problemática se pronuncia en el artículo I.I b) lo que conlleva al análisis de las normas de conflicto cuando no se determina la ley que regirá el contrato; sin embargo antes de esto se deberá tomar en cuenta la autonomía conflictual en relación para resolver en primer aspecto lo controvertido, de no ser así la norma conflictual pudiera tener asidero al momento de la escogencia de una ley aplicable y en el derecho moderno esta norma no solo debe tener en cuenta la escogencia de un derecho nacional para dirimir un conflicto sino que es admisible el reconocimiento de la Lex Mercatoria o usos y costumbres que así dispongan las partes cuando se procura suplir la ausencia de regulación legal adecuada para el negocio jurídico.

Analizada la Convención es necesario puntualizar que su implementación ha sido de vital importancia para el desarrollo del comercio internacional sobre todo en la búsqueda de un derecho uniforme. Como bien mencione, aún existen vacíos que pueden superarse, sin embargo las reglas generales están claramente establecidas, en tal razón recomiendo que Nicaragua debe tomar parte de este instrumento internacional máxime que el auge comercial se encuentra en notable crecimiento, le procuraría una mayor seguridad jurídica para los inversionistas y para los nicaragüenses que pretendan incursionar o que ya son parte del comercio exterior.

\section{Lista de Referencias Bibliográficas}

Adame Goddard, J. (1994). El contrato de compraventa internacional. México: McGRAW-HILL.

Álvarez Vázquez, A. N., Arias Segura, M. G., De Mauleon Medina, C. C., González Enríquez, I., \& Hernández Rivera, L. E. (2005). Estudio sobre las aportaciones al Derecho Internacional Privado por la Convención de Roma sobre la ley aplicable a las Obligaciones Contractuales (1980) y sus limitantes por el Derecho Interno de los Países Contratantes. Revista del Centro de Investigaciones, 6 (23), 43-5I.

Andrade-Abularach, L. (200I). Los contratos de compraventa internacional de mercaderías. Guatemala: Serviprensa.

Campuzano Díaz, B. (2000). La repercusión del Convenio de Viena de I I de abril de 1980 en el ámbito de compraventa internacional de mercaderías. Sevilla: Pinelo Talleres Gráficos.

Cárdenas Mejía, J. P. (2003). La formación del contrato de compraventa internacional en la Convención de Viena. En Compraventa Internacional de Mercaderías. Comentarios a la Convención de Viena de 1980 (págs. 315-349). Colombia: Pontificia Universidad Javeriana.

Castellanos Ruíz, E. (20II). Convención de Viena de 1980 sobre compraventa internacional de mercaderías: Ámbito de aplicación, carácter dispositivo y disposiciones generales. Cuadernos de la Maestría en Derecho, (I), 77-I6I.

Castrillón y Luna, V. (2003). Contratos Mercantiles. Ciudad de México: Porrúa. 
Dávalos Fernández, R. (2003). La regulación jurídica del contrato internacional. Revista Cubana de Derecho, (2I), 4-56.

Díez Picazo, L. (20I0). Obligaciones y contratos en el derecho contemporáneo. Colombia: Universidad de La Sabana.

Escamilla Jaime, J. M. (20/3). El contrato internacional de compraventa de mercaderías. Un Instrumento fundamental en los negocios internacionales. Opciones, (5I), 35-56.

Fernández Rozas, J.C., Arenas García, R., \& De Miguel Asensio, P.A. (20I3). Derecho de los negocios internacionales (4 ed.). Madrid: lustel.

Ferrari, F. (2009). Fuentes aplicables a la compraventa internacional de mercaderías. Barcelona: Bosch.

Fratalocchi, A. (1994). Incoterms contratos y comercio exterior. Buenos Aires: Ediciones Macchi.

Galiana Saura, A. (20I6). La expansión del Derecho flexible y su incidencia en la producción normativa. AFD, (XXXII), 297-322.

Galán Barrera, D. (2003). La compraventa internacional de mercaderías y su integración en el ordenamiento jurídico colombiano. Criterio Jurídico, (3), 7-33.

Galán Barrera, D. R. (2004). La convención de las naciones unidas sobre los contratos de compraventa internacional de mercaderías. Estudios Gerenciales, 20 (91), 49-64.

Góngora Guzmán, D., \&Martínez Olivas, J. (2014). La oferta y la aceptación como procedimiento de formación del contrato en el código civil cubano. Derecho y Cambio Social, XI (25), I-24.

González Martin, N., \& Rodríguez Giménez, S. (2010). Derecho Internacional Privado. Parte General. México, D.F.: Nostra Ediciones.

Jaramillo Vargas, J. A., \& Martínez Granados, A. M. (2003). Formación del contrato en la convención de Viena sobre compraventa internacional de mercaderías: aplicación en el derecho colombiano. Revista e-mercatoria, (2), 25-49.

Juenger, F. K., \&Sánchez Lorenzo, S. A. (2000). Conflictualismo y Lex Mercatoria en el Derecho Internacional Privado. Revista Española de Derecho Internacional (LII-I), I4-47.

Leible, S. (20II). La importancia de la autonomía conflictual para el futuro del derecho de los contratos internacionales. Cuaderno de Derecho Transnacional, 3 (I), 2I4-233.

López Guzmán, F., Sánchez Morgestein, W. I., \& Quiroga Alarcón, H. A. (2009). Compraventa internacional de mercaderías. Investigación y enseñanza del Convenio de Viena de 1980. Studiositas, 4 (2), 23-37.

Lorente Martínez, I. L. (2015). Convenio de Roma 1980 y Reglamento de Roma I. Cuaderno de Derecho Transnacional, 7(I), 269-276.

Martínez Cañellas, A. (2004). La interpretación y la integración de la Convención de Viena sobre compraventa internacional de mercaderías. Granada: Editorial Comares, S.L. 
Medina de Lemus, M. (1992). La venta internacional de mercaderías. Madrid: Tecnos S.A.

Michinel Álvarez, M. A. (20I2). El Derecho Internacional Privado en tiempos hipermodernos. Madrid: Dykinson.

Navarro Pentón, A. G. (2009). Régimen Jurídico de la compraventa internacional de mercaderías en Europa y América latina. Un sistema suficiente? (Tesis inédita de doctorado), Universidad de Granada, España.

Ortega Giménez, A. (2008). Contrato de compraventa internacional de mercaderías. Confianza en el Comercio. Madrid: ICEX.

Ortega Giménez, A. (2009). El contrato de compraventa internacional de mercaderías. vLex International, (4), I-26.

Orúe Cruz, J. (20|4). Manual de Derecho Mercantil (3 ed.). Managua: Hispamer.

Oviedo Albán, J. (2003). Aproximación al sistema de fuentes del contrato de compraventa internacional de mercaderías. International Law: Revista Colombiana de Derecho Internacional, 103-I56.

Oviedo Albán, J. (2003). Instituciones jurídicas en procesos de integración y globalización: la formación del contrato de compraventa internacional de mercaderías. Vniversitas, ( I05), 463552.

Oviedo Albán, J. (2004). Aplicación directa de la convención de Naciones Unidas sobre los contratos de compraventa internacional de mercaderías. Revista Colombiana de derecho Internacional, (4), 73-94.

Oviedo Albán, J. (2009). Aplicación material de la convención de naciones unidas sobre compraventa internacional de mercaderías. Colombia: Red Vniversitas.

Oviedo Albán, J. (20ll). Estudios sobre la compraventa internacional de mercaderías. Aplicaciones jurisprudenciales. Saarbrucken: Editorial Academia Española.

Oviedo Albán, J. (20II). La Convención sobre compraventa internacional de mercaderías. Buenos Aires: ILADEN.

Oviedo Albán, J. (20I2). La ley aplicable a los contratos internacionales. Revista colombiana de Derecho Internacional, (2I), II7-I57.

Piltz, B. (1998). Compraventa Internacional. Buenos Aires: Astrea.

Santos Belandro, R. B. (2006). La compraventa internacional de mercaderías y la aplicación del Tratado de Viena en Ecuador y Uruguay. FORO. (5), 5-47. 